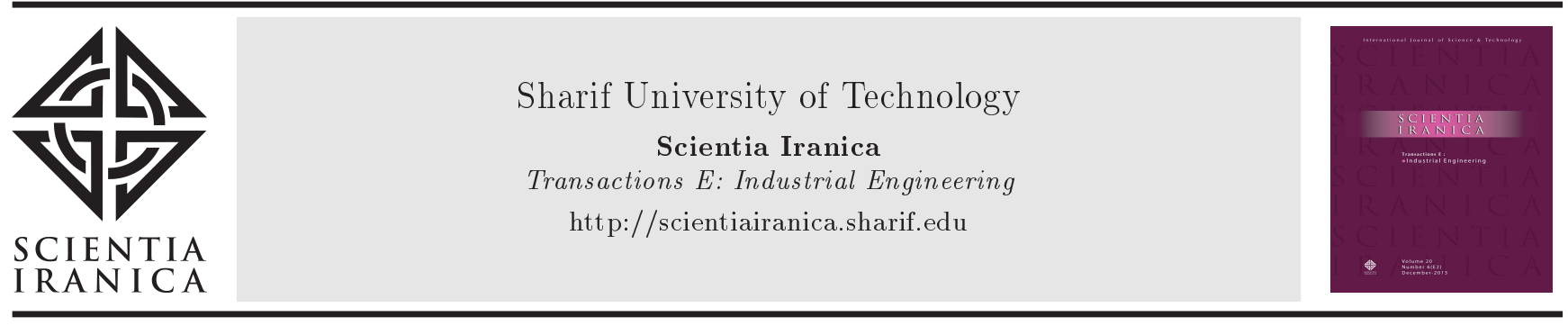

\title{
A framework for earthquake emergency response in Iran
}

\author{
M. Najafi ${ }^{a, *}$ S. Eshghi ${ }^{b}$, and K. Eshghi ${ }^{a}$ \\ a. Department of Industrial Engineering, Sharif University of Technology, Azadi Ave., Tehran, Iran. \\ b. International Institute of Earthquake Engineering and Seismology (IIEES), Tehran, Iran.
}

Received 8 May 2018; received in revised form 25 November 2018; accepted 26 January 2019

\section{KEYWORDS}

Disaster management; Earthquakes;

Emergency response;

Response framework;

Earthquake loss

mitigation;

Iran.

\begin{abstract}
Earthquake is a common natural disaster in Iran, often accompanied by huge damages, losses, and casualties. Therefore, focusing on earthquake response management and improving its effectiveness is an important issue for the national disaster management organization. This paper proposes a framework to improve this process in Iran. The proposed framework attempts to coordinate governmental and non-governmental organizations involved in earthquake response. It also allows governments to systematize the obligations and responsibilities of these organizations and mitigate the earthquake fatalities and casualties. Moreover, this study discusses the key considerations for implementing the proposed framework and analyzes it on distinct scales of an earthquake.
\end{abstract}

C) 2020 Sharif University of Technology. All rights reserved.

\section{Introduction}

Recent increases in geological, oceanic, and atmospheric disasters $[1,2]$ have forced governments to consider disaster responses. A common natural disaster is earthquake, often accompanied by huge damages, losses, and casualties. Though thousands of networked seismograph stations are installed worldwide and powerful computers continuously analyze the data generated by these stations, we remain unable to predict exactly when and where earthquakes will strike [3]. This uncertain and unpredictable characteristic along with increased population congestion results in huge damages and casualties. Table 1 presents some of such catastrophes and their effects.

Generally, Iran has the highest seismic risk in the

\footnotetext{
*. Corresponding author. Tel.: +98216616 5709 E-mail addresses: najafi.mehdi@sharif.edu (M. Najafi); s.eshghi@iiees.ac.ir (S. Eshghi); eshghi@sharif.edu (K. Eshghi)
}

doi: $10.24200 /$ sci.2019.50985.1951 region. As is shown in Table 1, Iran has suffered large and devastating earthquakes, including the ManjilRudbar and Bam earthquakes, which have caused heavy casualties and widespread economic losses over the last decades.

Although a local community performs response activities in a small or rural earthquake [4], this community cannot perform these activities properly and purposefully in a large earthquake [5-7]. In this condition, the participation of both governmental administration (public) and private as well as local community is essential for success in disaster response [8]. In other words, diverse governmental or non-governmental organizations including individuals, local community, government institutions and departments, emergency services, military and international organizations and agencies are necessary to be involved in response efforts. In this case, government needs to create a systematic and proactive earthquake emergency response system to coordinate these activities in order to decrease the earthquake casualties, handle the complexity of earthquake response, and increase the response effectiveness [9-11]. 
Table 1. Casualties of some recent earthquakes.

\begin{tabular}{lclccc}
\hline \multirow{2}{*}{ Name of disaster } & \multirow{2}{*}{ Year } & Location & \multicolumn{3}{c}{ Estimated casualties } \\
\cline { 4 - 6 } & & & Dead & Injured & Homeless \\
\hline Sulawesi earthquake & 2018 & Indonesia & 2100 & 14,254 & 616,684 \\
Iran-Iraq earthquake & 2017 & Iran \& Iraq & 630 & 7,460 & 70,000 \\
Ecuador earthquake & 2016 & Ecuador & 676 & 16,600 & 140,000 \\
Nepal earthquake & 2015 & Nepal & 9,018 & 23,447 & $3,500,000$ \\
Ludian earthquake & 2014 & China & 617 & 3,143 & 230,000 \\
Bohol earthquake & 2013 & Philippines & 222 & 976 & $3,542,281$ \\
East Azerbaijan earthquake & 2012 & Iran & 306 & 5,000 & 306,000 \\
Tohoku earthquake & 2011 & Japan & 20,896 & $26,992^{*}$ & $450,000^{*}$ \\
Haiti earthquake & 2010 & Haiti & 316,000 & 300,000 & $1,300,000$ \\
Sichuan earthquake & 2008 & China & 69,195 & 374,177 & $5,000,000$ \\
Kashmir earthquake & 2005 & Pakistan & 86,000 & 69,000 & $4,000,000$ \\
Bam earthquake & 2003 & Iran & 31,000 & 30,000 & 75,600 \\
Manjil earthquake & 1990 & Iran & $>40,000$ & $>60,000$ & $>500,000$ \\
\hline
\end{tabular}

*: Data are extracted from East Asia Forum.

In the current situation, lack of a systematic and integrated response plan in Iran is the reason why the involved organizations and individuals commonly use their own facilities and capabilities to help the affected people without pursuing a central and integrated plan [7]. That is, after an earthquake strikes, several governmental and non-governmental organizations usually start relief operations according to their own agendas and use their own facilities and capabilities to help the affected people without any coordination with other organizations or pursuing a central plan. These contradictory behaviors usually cause many problems in disaster emergency response such as resource waste, and inequity of service for all affected people. In order to avoid this condition, these communities (local and global) should perform their activities as a subgroup of activities defined in an integrated framework $[5,7,12]$.

Given our discussion of earthquake responding, several important aspects of earthquake emergency response management in this research study are addressed. Firstly, this study discusses the impacts of the disintegration of organizations involved in earthquake emergency response on the quality of response. Secondly, it identifies and investigates the activities that should be performed in earthquake emergency response. In addition, the priority of each activity on different scales of an earthquake is considered. Thirdly, the prerequisite of implementing an integrated emergency response being important for real cases is debated in this study.

The remainder of this paper is organized as follows. Section 2 reviews the relevant literature to position this study among existing works and reveals its novel aspects. Section 3 explains the problem in detail, and Section 4 discusses the research method for identifying the earthquake emergency response activities and providing the response framework. This study proposes an integrated Earthquake Emergency Response Framework (EERF) in Section 5 and discusses its prerequisites for the efficacious implementation of EERF in Section 6. Finally, Section 7 analyzes the proposed framework and determines the activities that should be performed on various scales of an earthquake. Section 8 provides a conclusion and suggests future studies.

\section{Literature review}

Despite the importance of coordination and integration in emergency response, this area has not received enough attention by researchers in the last years. Existing literature demonstrates that most of the previous studies have not focused on the integration of activities and have tended to work on logistics support (as a group activity) due to its complex nature and significant effect on rescuing injured people. Hence, the literature can be categorized into two groups from this point of view. The first category focuses on logistics planning. These research papers aim to handle the transfer of the injured people from the affected area to temporary or permanent hospitals and distribute essential commodities from available sources to demand points in the affected area. However, the second group of research concentrates on earthquake emergency response as a whole. 


\subsection{Research studies that focus on logistics planning}

Many researchers have focused on this subject since the late 1980s. These research papers can be categorized into three groups. The first group focuses on handling the logistics of injured people and commodities in the response phase [3,13-36], and the second group uses some qualitative factors to improve the disaster response [37-39]. It is worthy to note that studies of the first group often focus on developing a mathematical model to plan either the logistical commodity support, or transporting injured people, or both. Contrarily, studies of the second group focus on qualitative methods to improve the emergency response. For instance, $\mathrm{Yi}$ and Ozdamar [31] presented a dynamic logistics coordination model for evacuation during the disaster response phase, whereas Kurita et al. [38] applied statistical techniques to analyze public awareness of natural disasters and propose several methods for reducing casualties. The last group of studies such as $[40,41]$ focuses on affected people rescue. They attempted to use a mathematical model to improve the performance of resources utilized for searching for those trapped in disaster regions or the time required for rescuing injured people. Given the extensive research in this category, we mainly focus on relevant studies that belong to the second category, i.e., studies focused on earthquake emergency response as a whole.

\subsection{Research studies that focus on earthquake response procedure}

As mentioned earlier, this area of research has not received much attention from researchers. Based on our best knowledge, Yi and Kumar [42] is the first study that focused on this issue. They defined five phases in their proposed logistics system. These phases are timevarying relief demand forecast, affected area grouping, determining distribution priority, group-based relief distribution, and dynamic relief supply. They only focused on developing a system for dispatching commodities and did not consider activities that should be performed for injured people or controlling the response plan. Stepanov and Smith [28] in a study focused on earthquake response management. They divided the response process into six stages in their proposed model. These stages were rapid assessment to identify the magnitude of the disaster, provide basic needs and basic health care services to attend to emergency care, surveillance and monitoring, organize human resources, and coordinate planning and service delivery activities among local authorities. This model is more complete than that proposed by $\mathrm{Yi}$ and Kumar [42]. However, it considered neither the relations of these activities nor their priorities during the earthquake response. In addition, none of them focused on earth- quake emergency response integration or coordination comprehensively.

Chen et al. [43] proposed a framework to analyze emergency response coordination patterns. They used semi-structured interviews with 32 emergency response personnel including town, city, county, and state emergency managers and Federal Emergency Management Agency (FEMA) coordinators for designing this framework. The proposed framework captures nine challenges, and appropriate support activities should be performed to deal with these challenges. Although this framework is useful for emergency response management, it does not investigate process flow and the priority of activities in emergency response management. Another research investigated the response coordination in earthquake emergency response [44]. This study designed a decision-making model to improve coordination in the large-scale emergency response. The proposed model was developed based on state-based forward hierarchical task network planning and scheduling technology and ab attempt was made to generate a temporary response plan that takes into account requirements of the emergency command operations. Although this model is more complete than the ones proposed by earlier researchers, it is a general model that creates required tasks of emergency response and does not focus on earthquake emergency response. Finally, prerequisite relations among tasks or activities are not investigated in this research. Another study that pays attention to the emergency response as a whole is [45]. Although this research does not present any framework or model for the earthquake emergency response, the proposed scenario-based model is an appropriate tool for the evaluation of the effectiveness of earthquake management work. This study uses Delphi method, cross-impact method, and interpretive structural modeling to improve earthquake emergency management.

Despite similarities in the literature, the current study focuses on a different aspect of earthquake emergency response that has not been investigated by previous studies. This aspect and the major contributions of our study are summarized below.

Firstly, this study identifies the activities required in earthquake emergency response and captures the presence of prerequisite relations among these activities. Secondly, since emergency situations are complex, this research develops a framework to coordinate and integrate activities performed in earthquake emergency response in Iran. Thirdly, a process is developed using the proposed framework to coordinate and control the response activities in earthquake emergency response. Fourthly, this study discusses the implementation consideration and determines the prerequisite infrastructures and tools for implementation. Additionally, this research study customizes the process's activities for 
different scales of an earthquake and determines their importance by Analytical Hierarchy Process (AHP) technique.

\section{Problem statement}

In order to remove the inconsistency of earthquake emergency response in Iran [7] considered the existing organization of earthquake emergency response and proposed an arrangement for the earthquake emergency response. In this arrangement, a Planning and Emergency Center (PEC) is proposed that deals with the disaster cycle as a whole rather than postdisaster events. This center, at the national level, will be responsible for the planning and ordering of the research needed into earthquake disasters. The results obtained will then be shared and used by the state and city level PECs to lead earthquake emergency response. However, he did not determine the activities that should be performed by these state PECs. In addition [46] emphasized that Iranian disaster management system required a sustainable long-term framework to unify the decision-making processes, the efforts of various organizations and institutions, and local communities towards an integrated earthquake response. This PEC was formed as a supreme council in the National Disaster Management Organization (NDMO) in 2008. This council is chaired by the President of the country, and its members are 13 ministers, Mayor of Tehran, Commander of Armed Forces, one of the deputies of the Speaker of the Islamic Consultative Assembly (the Parliament), first deputy of the Judiciary, Heads of Management and Planning Organization, the Islamic Republic of Iran Broadcasting Corporation, Head of Red Crescent Society of the Islamic Republic of Iran, Imam Khomeini Relief Committee, Head of State Meteorological Organization, Head of Housing Foundation of the Islamic Revolution, and the Head of NDMO [47]. As mentioned earlier, this PEC should have an integrated framework to harness the energies, purposes, and goodwill of various individuals and organizations involved in an earthquake response. This framework not only assists the PEC or disaster managers to decrease redundancy (increase the efficiency of initial activities), but also helps them to identify the appropriate organizations for responding. In addition, the framework assigns response activities according to the proficiencies and equipment of these organizations. This structure also helps disaster managers evaluate these organizations' performance, identify the weakness of response, and improve the response to the next earthquake.

Due to the necessity of this framework, this paper aims to identify the activities that should be performed in an earthquake emergency response and presents an integrated framework for an earthquake emergency response in Iran. This framework manages the response activities purposefully and is applicable in an area in which some basic facilities, services, and equipment are available. Furthermore, this paper discusses the prerequisites of framework implementation and analyzes the framework at various earthquake scales.

\section{Research methodology}

This study considers the activities that should be performed by the Iranian PEC in an earthquake emergency response. It also investigates the sequences and relations of these activities as an integrated framework. As is shown in Figure 1, in the first step of the study, the literature was investigated to identify those activities that must be performed in the earthquake response. This review showed that the previous studies did not consider this issue and the integrated response model that is needed during the earthquake response. Then, the reports generated in the earlier earthquakes, such as $[2,48]$, were investigated to identify the activities performed in the earthquake responding.

These studies and reports were used for identifying different categories of necessary activities in an earthquake emergency response. These categories of activities were then analyzed, and their relations were determined. In the next step, the initial list of activities that should be performed in each category was determined. Afterward, this list was utilized for preparing interview questions (the Appendix). These questions were then used for conducting semi-structured interviews with 15 experts who had good experience in earthquake disaster response in Iran. The collected data were used for finalizing the list of activities that should be performed on various scales of earthquake and defining the response framework. By determining the activities that should be performed in each earthquake, the importance and priority of categories and activities were determined by utilizing the AHP technique in the next step. In order to determine these importance coefficients, five tables were designed for pair-wise comparison of these activities at each scale of earthquake. These tables were given to 15 experts and disaster managers. These pair-wise comparisons were analyzed, and the corresponding inconsistencies were calculated in the next step. As the data collected from three experts were inconsistent, their opinions were removed. Hence, the opinions of twelve experts were analyzed, and the importance of the activities was determined at each scale of earthquake. It is worthy to note that, as shown in Figure 1, two parallel and complementary paths were used to validate the defined framework. On the one hand, several experts were interviewed about the proposed framework elements including activities and the relations among them, and their comments were applied to revise the framework 


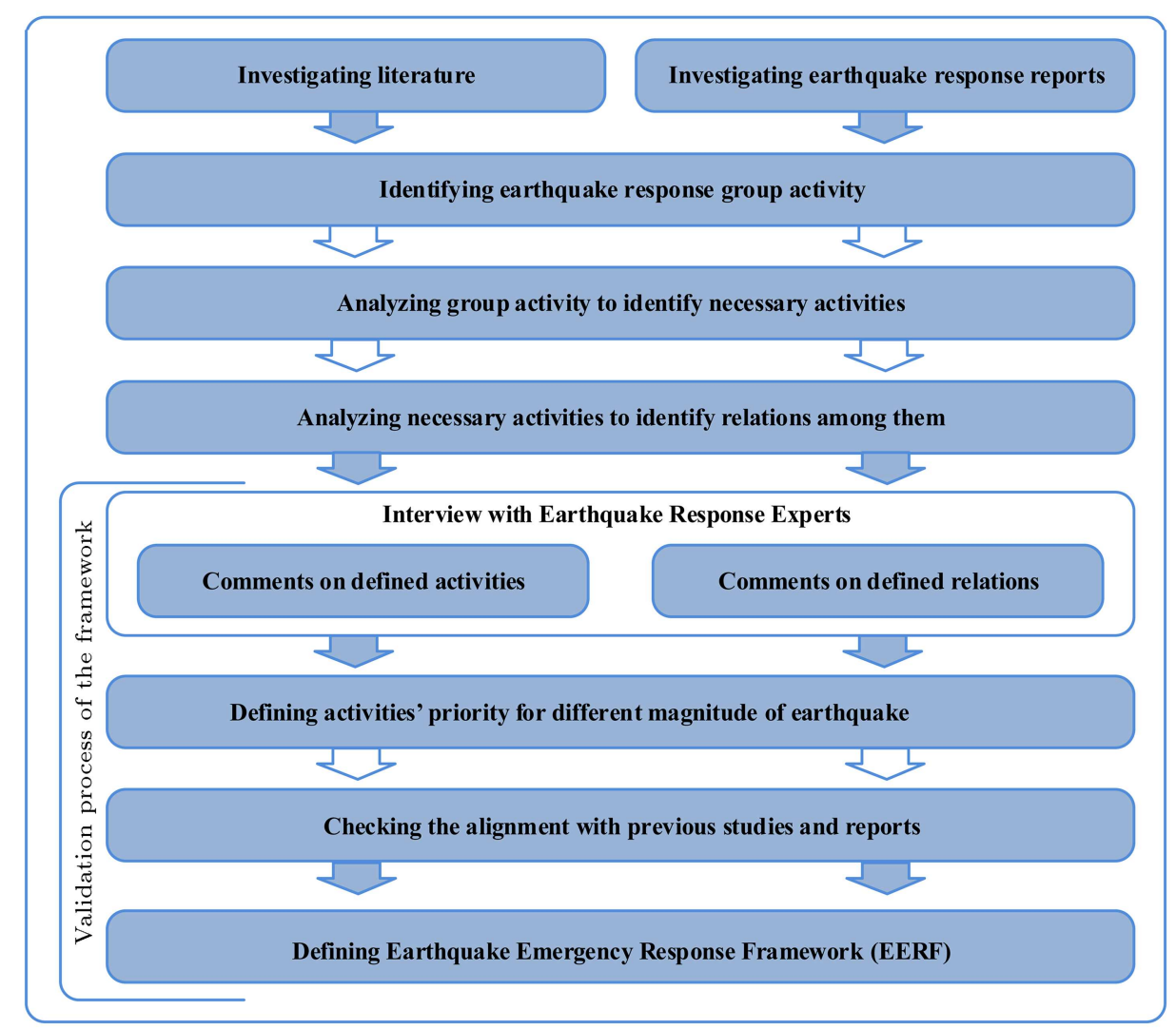

Figure 1. Research methodology for Earthquake Emergency Response Framework (EERF) definition and validation.

(as it will be stated in the next section). On the other hand, the proposed framework was compared to previous earthquake response studies and reports to ensure that there is no conflict between them. These two issues can give the user confidence about the validity of the proposed framework.

\section{Proposed integrated framework for earthquake emergency response}

Logistics support and evacuation generally constitute the main body of earthquake response. However, they are not the whole response $[28,42,48,49]$. As these studies mention, some other tasks should be performed in earthquake response. For instance, initial identification should be performed to identify the magnitude and location of earthquake and the available supplies and capacities. In addition, several studies $[2,17,37,50]$ recommend that the other series of activity that should be performed in an earthquake emergency response are as follows:

- Estimation;

- Planning;

- Execution;

- Supporting and Surveillance.
As Figure 2 shows, the initial setup identifies the magnitude and location of earthquake and updates the emergency response database by re-reading the available information about available suppliers and their stocks, available hospitals and their capacities, transportation networks, and other entities from the available databases. Then, estimation group activity appraises earthquake losses by the information received from the initial identification and emergency response database. Afterward, the planning group activity receives the information of losses and supplies, capacities, and equipment from the estimation group activity and emergency response database, respectively, and analyzes this information to produce the emergency response plan. Then, execution group activity implements the generated plans. Finally, supporting and surveillance group activity supervises and monitors the activities performed in an emergency response.

The investigation of the literature demonstrates that the estimation group activity comprises several important activities [6,51]. These activities should consider two areas. The first one is the relief crews and equipment required for the response, and the second one is the number of affected and wounded people and the number of commodities required for these people. This group activity should also analyze these estimations (including needs, supplies, and injuries and the 


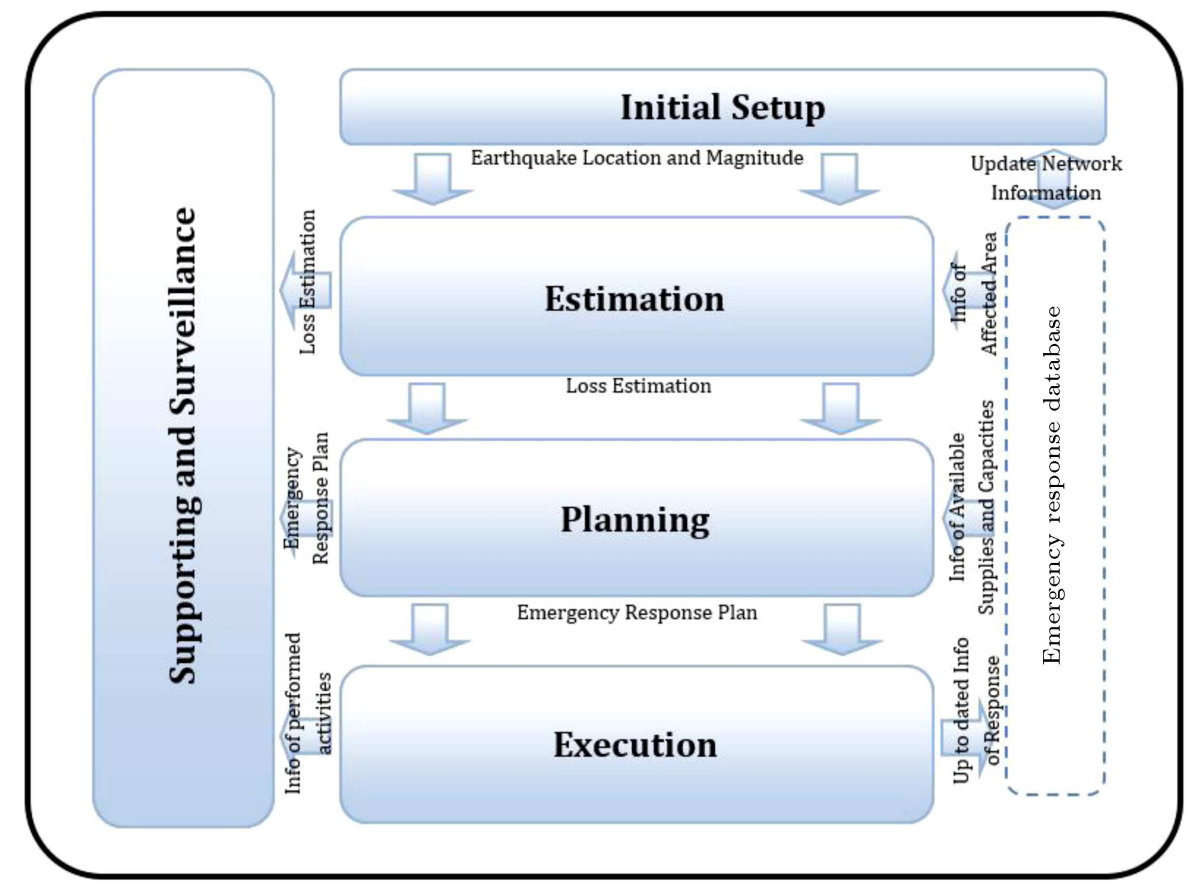

Figure 2. Relations between various group activities of earthquake emergency response.

capacity of hospitals) to predict possible deficiencies. Therefore, this group activity includes three activities:

- Estimating relief crews and equipment;

- Estimating needs and the number of injuries;

- Estimating deficiencies.

Decision-making is one of the most important tasks in disaster response management [52]. Hence, the second group activity, planning activities, should make decisions on logistical support and resource assignment according to the estimations. It also examines the response circumstances and determines whether the response continues or not. The previous research and reports on earthquake response help us to define this group activity as follows:

- Planning relief crews and equipment [1,53];

- Planning logistics of needs and injuries [16,18,21];

- Planning response continuity [20].

An investigation of the reports generated in earlier large earthquakes $[48,49,54]$ demonstrates that the executing activities performed during the earthquake response are as follows:

- Initial identification;

- Dispatching relief crews and equipment;

- Organizing local relief crews;

- Extricating corpses and wounded people;

- Providing and dispatching needs;
- Transporting wounded people;

- Temporary relocating affected people.

Since the regional resources are usually insufficient, international or national public humanity assistance should be collected to meet the needs of the affected people. Hence, the following activity should be performed in an earthquake emergency response:

- Coordinating to collect public assistance.

Finally, in order to analyze and evaluate the involved organizations in the earthquake response, the following activity has been added to the activity list:

- Analyzing behaviors and evaluating efficiency.

As mentioned above, the Appendix presents the obtained list given to several disaster managers as a questionnaire form. They were asked to fill out the form based on their experiences. The results acquired from analyzing the fifteen completed forms confirm the initial list. They also added two activities to the initial list: locating focal points and replacing surplus commodities. These activities are added to the executing group activity and supporting and surveillance group activity, respectively. Hence, as is shown in Figure 2, the list of necessary activities of response reaches the following 17 activities;

\section{A-1. Initial assessment and identification}

The first activity of the response is initial identification. This activity accurately determines the magnitude of an earthquake and its location. Moreover, 
this activity re-examines the initial information about the affected area, available suppliers and their stocks, available hospitals and their capacities, transportation networks, and other entities involved in the response;

\section{A-2. Locating focal points}

Access to precise and up-to-date information is a prerequisite of a suitable response. Some trained people should be located on the response network as connectors between the PEC and relief chain entities. The main responsibilities of these people, who are called focal points, are registering data and transmitting up-to-date information to the PEC. This information clearly helps the disaster manager make correct decisions. Of note, to assign proper focal points, the earthquake and its effects should first be identified. Therefore, initial identification (A1 ) is a precedent activity for locating focal points. Moreover, because information transmission should be performed continuously, at least two trained people should be at each predefined point. Finally, the located focal points should first update their information about the works performed in their scope of responsibility and submit this information to the PEC;

\section{A-3. Estimating relief crews and equipment}

This activity estimates the number of relief crews, equipment, and tools including loaders and spades required for search, evacuation, extrication, and rescue. This activity requires data and information either generated in the initial identification (A-1) or received from the local focal points to increase the estimation precision;

A-4. Estimating needs and the number of injuries

Appropriate estimation of the numbers of survivors, injured people, dead and the amounts of required commodities for survivors is an important part of an earthquake emergency response. This activity uses the information generated in the initial identification (A-1) to estimate the initial needs of consumable and inconsumable commodities for survivors and wounded people and uses the information received from focal points to update these forecasts for the next periods;

\section{A-5. Planning relief crews and equipment}

This activity appropriately assigns available relief crews and equipment to the affected points. It also uses information about available crews and equipment as well as the information generated in estimating relief crews and equipment (A-3) to assign the available relief crews and equipment. Moreover, this activity uses the information received from focal points to consider the sufficiency or insufficiency of the available crews and equipment and meet the related needs;

A-6. Dispatching relief crews and equipment This activity aims to execute decisions made on planning relief crews and equipment (A-5). This activity moves the relief crews and equipment to the affected area based on decisions made in the previous activity (A-5);

\section{A-7. Organizing local relief crews}

A review of the past major earthquake responses demonstrates that the role of local individuals in earthquake response is irrefutable. To prevent inconsistencies and use the available capabilities, some dispatched relief crews organize the local relief crews and assign them some jobs. For instance, a group of crews is responsible for establishing temporary medical centers, another group is involved in setting up the commodity storage centers in the affected area, and so on. It is worthy to note that this activity aims to utilize the ability of local individuals to respond in order to expedite the search and rescue operation. These local relief teams contain individuals who passed required courses, and their grades are known. Moreover, because the dispatched relief crews organize the local crews, the activity A-6 is a precursor of this activity;

A-8. Extricating corpses and wounded people As mentioned above, this activity is important in earthquake emergency response. In this activity, the dispatched relief crews to the affected area extract the wounded people and corpses from the rubble. Note that the proper execution of this activity significantly affects casualty reduction. Moreover, this activity should be executed after the activity A-6 because relief crews and equipment perform it;

\section{A-9. Estimating deficiencies}

This activity investigates the sufficiency or insufficiency of available stocks and capacities according to information either generated in estimations (A-4), or received from resources, including focal points, suppliers, warehouses, and hospitals. In addition, if there is insufficiency, this activity determines the amount of shortage that should be satisfied by national or international assistance;

A-10. Coordinating to collect public assistance If there is insufficiency, international or national public humanity assistance should be collected to meet the needs of the affected people. In this case, some organizations, i.e., airline companies or customs, should be coordinated to convey the collected commodities to affected areas rapidly. This activity is defined to provide these necessary conditions. Furthermore, this activity should be managed purposefully. Otherwise, these collected commodities may not only fail to 
meet the needs but may also create problems in the response. For instance, some collected commodities may be out of date, or some may not be required at all. It is thus recommended that people be encouraged to help monetarily;

\section{A-11. Replacing the surplus commodities}

As mentioned in the previous activity, monetary assistance is preferred to commodities because money can help responders provide the demanded commodities. If the collected assistance comprises unnecessary commodities, this activity exchanges them for the necessary commodities;

A-12. Planning logistics of needs and injuries Logistics planning is an important part of earthquake emergency response [1]. This activity aims to plan the logistics for commodity and wounded people, considering both the estimations (A-4) and information received from the focal points. This activity determines how the wounded and commodities are transported, which routes are chosen for transportation, and which modes or vehicles are utilized for any movement. Moreover, this activity determines which commodities should be purchased from local vendors and which should be sent from central warehouses or vendors. Finally, it is worthy to note that because response conditions, i.e., hospital capacities or available supplies, are uncertain during the response, plans should be dynamically updated corresponding to up-to-date data;

\section{A-13. Providing and dispatching needs}

Generally, activities A-13 and A-14 are performed to complete action A-12. In this activity, the responder uses the plans produced in the activity A-12 to provide commodities from suppliers and dispatch them to the affected areas. In other words, this activity executes the plans produced in the activity A-12. Note that the located focal points are closely associated with this activity. They should follow cargo loading at supplier nodes and unloading at demand nodes to update the network status, including the number of available vehicles at a specific node, number of available commodities in a specific warehouse, and number of unsatisfied demands at a demand node;

\section{A-14. Transporting wounded people}

This activity also executes the plans produced in the activity A-12. In this activity, the responder uses the produced plans to manage the transfer of the injured people from affected areas to emergency medical centers or hospitals. Similar to the activity A-13, this activity is closely associated with the located focal points. In this activity, the located focal points should follow picking up the wounded at affected nodes and delivering them to hospitals to update the network status including the number of available vehicles at a specific node, available capacity in a specific hospital, and the number of wounded people at a demand node. They should also identify the injured people delivered to hospitals using a unique attribute, i.e., national code or fingerprint that is already registered in a central integrated system. This can help the managers and families of injured persons locate the injured and track their status;

\section{A-15. Temporary relocating affected people}

This activity aims to relocate the survivors temporarily and distribute the received commodities among them. In this activity, an appropriate central place should be chosen and the survivors should be located centrally. This centralized location makes commodity distribution easier, fairer, and more equitable. In addition, this activity is responsible for the remaining properties of affected people and attempts to organize and protect the remaining valuable things;

\section{A-16. Planning response continuity}

This activity investigates the circumstances of the survivors and affected areas and determines the necessity of response continuity. If the survivors' conditions do not reach a steady state, some response activities continue. Otherwise, the response phase is terminated and the recovery phase starts;

\section{A-17. Analyzing behaviors and evaluating ef- ficiency}

Finally, all reports and information generated in each response activity are analyzed, and all organizations involved in the response are evaluated. This activity does not generate the reports; it only analyzes and documents the reports produced in the previous activities. Furthermore, the experiences and knowledge obtained in the earthquake emergency response are documented in this activity for improving response efficiency and effectiveness in later cases.

According to the presented description of activities and their relations, the EERF and its flow are depicted in Figures 3 and 4, respectively. In addition, the operational decisions that should be made during the process are depicted in Table 2.

Note that these activities usually need different execution times in distinctive earthquake situations. For instance, the activity A-8 (extricating corpses and wounded people) needs more time in a large earthquake. Contrarily, it may require less time in a small earthquake. Moreover, the different natures of these activities make their execution times different. For example, the time required for planning needs and wounded people logistics (A-12) differs from the time required for transporting wounded people (A-14). The proposed framework considered these execution times and determined the critical path in the earthquake emergency response (the bold activities and path). 


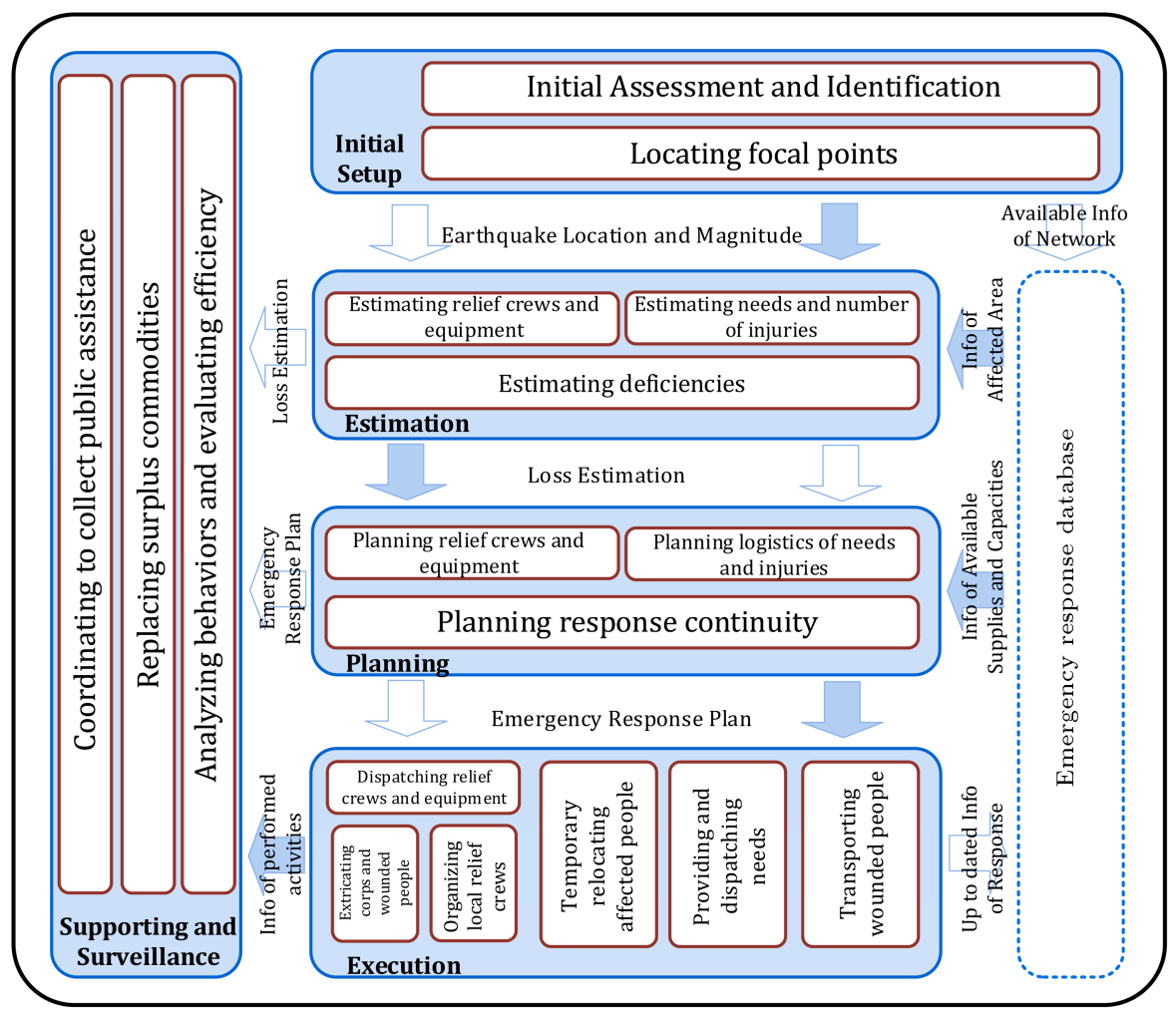

Figure 3. Necessary activities of Earthquake Emergency Response Framework (EERF).

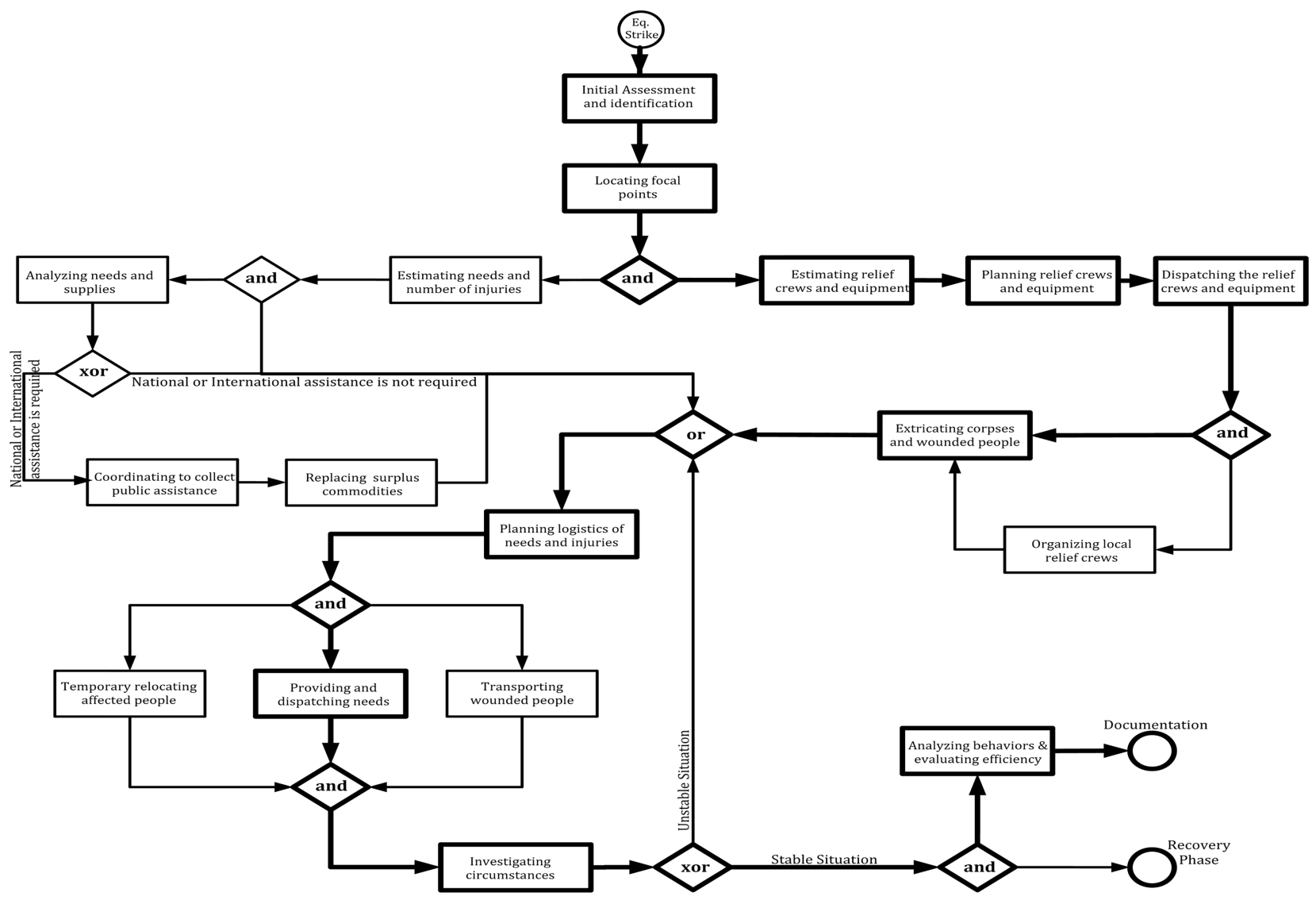

Figure 4. The proposed earthquake emergency response flow. 
Table 2. Key operational decision during the response.

\begin{tabular}{lll}
\hline No. & \multicolumn{1}{c}{ Activity } & \multicolumn{1}{c}{ Key operational decision } \\
\hline A-1 & Initial identification & Initial parameter estimation and updating \\
A-2 & Locating focal points & Number and location of focal nodes \\
A-3 & Estimating relief crews and equipment & Number of crews and equipment \\
A-4 & Estimating needs and the number of injuries & Number of injured people, and amount of demands \\
A-5 & Estimating deficiencies & Capacity management and planning \\
A-6 & Planning relief crews and equipment & Relief scheduling and management \\
A-7 & Planning logistics of needs and injuries & Logistics planning \\
A-8 & Planning response continuity & Response horizon \\
A-9 & Dispatching relief crews and equipment & - \\
A-10 & Organizing local relief crews & - \\
A-11 & Extricating corpses and wounded people & - \\
A-12 & Providing and dispatching needs & Inventory management \\
A-13 & Transporting wounded people & - \\
A-14 & Temporary relocating affected people & Layout management \\
A-15 & Coordinating to collect public assistance & - \\
A-16 & Replacing surplus commodities & Replacement policy \\
A-17 & Analyzing behaviors and evaluating efficiency & - \\
\hline
\end{tabular}

This path determined based on the time is required to perform the activity and does not specify the importance of activities. As an example, consider transporting wounded people activity (A-14). Since this activity needs less time than providing and dispatching needs (A-13), it is not in the critical path. However, it is an important activity and any fault in its performance can significantly increase casualties. Finally, it is worthy to note that the inappropriate execution of each activity may cause disorder in the earthquake emergency response. Therefore, to avoid increased fatalities, it is important that all essential activities in an earthquake emergency response be performed accurately.

\section{The key considerations for EERF Implementation}

Although the proposed framework can be implemented in any circumstance, its proper and perfect implementation obviously requires some prerequisites and conditions. Some conditions and prerequisites were mentioned in Section 1, and others are given below:

a. Determining the organizations involved and defining their obligations and responsibilities A common problem in earthquake emergency response in Iran is the overlapping responsibilities of organizations involved in the response. These overlaps either lead to redundancies or prevent the performance of some works. To solve this problem, the organizations involved in an earthquake response and their obligations, responsibilities, and authorities should be defined before a disaster strikes; b. Preparing a centralized up-to-date database As mentioned above, most of the defined activities require accurate and up-to-date information. For instance, initial identification activity must re-examine information about the affected area, suppliers, hospitals, and other entities involved in responding. Moreover, the second activity needs information about the trained people to locate them as focal points. Estimating needs and number of injuries (A4) also requires information about the affected area including population and region properties. In addition, planning the logistics for needs and wounded people (A-12) obviously needs precise and up-todate information about available vehicles, hospitals' capacity, and suppliers' stocks. Therefore, a centralized up-to-date database should be prepared to provide this information for the mentioned activities. This database must store several cases of information including population, facilities, residential areas' situation, transportation network, relief suppliers, hospitals, and trained people or organizations;

\section{c. Providing appropriate decision support sys- tems}

Decision-making is one of the most important tasks in the EERF framework. The lack of criteria regarding the decisions made in disaster response can lead to unforeseen factors and threaten the quality of response [52]. These decisions are often complex, and disaster managers of PEC cannot make them accurately without decision support systems. The decisions made for dispatching commodities (A-12), transporting injured people (A-12), and assigning relief crews and equipment (A-5) are complex in a large-scale earthquake. In this case, the PEC 
needs some systems or models for making a decision about these activities in the response phase. Thus, providing appropriate decision support systems is an important prerequisite for the proper and efficacious implementation of EERF. Previous studies have investigated this subject and proposed several valuable models to help responders in these decisions. Many studies have presented a model to plan wounded people transportation $[27,28]$, commodity dispatching $[3,21,29,30,32,33]$, or both commodity and wounded people transportation $[18,20,27,31,34-$ 36,42]. Furthermore, some researchers attempted to prepare a condition for appropriately assigning relief equipment [53]. However, no model uses the estimation method to estimate the wounded people, needs, and required relief equipment considering the number of the population affected, earthquake scale, and other related factors, as indicated in [18]. Therefore, the necessary tools should be provided to make appropriate decisions during the response;

\section{d. Educating the involved organizations}

Educating the organizations and persons involved in a response should be considered for the efficacious implementation of EERF. A person located as a focal point in the network should know which cases of information are important and how this information should be collected. Moreover, the relief crews should learn how they search for and rescue the injured people, organize local crews, and report situations to the respective entities. These trained persons are categorized according to their skills and obligations, and their responsibilities are determined according to their grades;

\section{e. Providing the required infrastructure and equipment}

Another factor in the proper implementation of EERF is providing the required infrastructures and equipment. These infrastructures and equipment usually help the PEC to cooperate and integrate the responder organizations. Several pieces of equipment should be provided to prepare an online communication between the focal points and the PEC. Furthermore, the required permission and authorities should be prepared for the PEC to access the required database for its decision-making. Moreover, the required equipment or machines should be provided and delivered to hospitals or medical centers, enabling them to register information about the wounded people and transfer this information to the PEC. There are several other instances for this necessary equipment changing according to response quality.

In addition to the introduced factors, other factors may influence EERF implementation. These factors are usually determined corresponding to the situation of the place where the framework is implemented. Note that although the lack of these factors does not make EERF implementation impossible, it does reduce its efficiency and effectiveness. The responder should thus provide as many of these factors as possible before starting the response.

\section{Adjusting EERF for different scales of earthquake}

Although the proposed framework handles several activities to respond to an earthquake, there is no necessity to perform all activities in all earthquake emergency response cases. The responders should consider various factors including the earthquake scale, available equipment, and response policy to choose part or all of these activities for an appropriate earthquake emergency response. Since the earthquake scale is the most widespread factor, this section investigates this factor and its impact on using EERF.

The earthquake scale is the degree of the earthquake's intensity and its effects on the earth's surface. Wood and Neumann [55] developed this scale, which differs from the earthquake magnitude measured on the Richter scale. According to this scale, an earthquake's intensity is categorized in 12 degrees, I to XII. For simplicity, these 12 degrees of earthquake are classified into four categories:

Category 1: Light earthquake. A light earthquake is an earthquake with a degree of I-III on the Modified Mercalli scale;

Category 2: Small earthquake. A small earthquake is an earthquake with a degree of $I V-V$ on the Modified Mercalli scale;

Category 3: Medium earthquake. A medium earthquake is an earthquake with a degree of VI-VII on the Modified Mercalli scale;

Category 4: Large earthquake. A large earthquake is an earthquake with a degree of VIII-XII on the Modified Mercalli scale.

These categories are defined based on the Modified Mercalli scale and do not consider the Richter scale [55]. A large-scale earthquake may be an earthquake with magnitude 6.6 on the Richter scale in some cases, such as the Bam earthquake in 2003, or an earthquake with magnitude 9.0 on the Richter scale, such as the Tohoku earthquake in 2011. An earthquake with a specific magnitude, e.g., 6.6 on the Richter scale, may be a small earthquake in a place like Japan. Conversely, this earthquake is a large earthquake in a place like Bam, accompanied by large casualties.

It is worthy to note that EERF is impressed by the earthquake scale. According to the description of the Modified Mercalli scale [55], a light earthquake needs no response. However, domain experts 
emphasized that the responder (PEC) must use part of EERF in response to the other earthquake categories. Although these categories of earthquake need a response, the activities performed in their responses are distinct. For instance, organizing the relief crews $(\mathrm{A}-7)$ is not required in response to a small earthquake; conversely, in response to a large earthquake, this activity should certainly be executed. Furthermore, the importance and priority of these activities are different on various scales of earthquake. In order to investigate the effect of earthquake scale on EERF use, two questionnaires are designed. The first one (Table A.1 in the Appendix) was utilized to determine the necessity of activities on various scales of earthquake. According to the judgments of 15 experts and disaster managers in Iran, Table 3 depicts the activities should be performed on three scales of earthquake.

Since a large earthquake is accompanied by huge damages, losses, and casualties, available resources are usually insufficient for responding to this scale of earthquake. As Table 3 shows, all defined activities should thus be performed rapidly and precisely for the response. However, in a medium earthquake, the available resources are usually sufficient for the response. There is thus no need to coordinate collecting the public national or international humanitarian assistance. The activities coordinating to collect public assistance (A-10) and replacing the surplus commodities (A-11) could be removed from the response. Finally, since the enforced damages, losses, and casualties are smaller in a small earthquake than those incurred in a medium or a large earthquake, regional responders can handle the response. In addition, because of small losses and damages, available resources are usually more than the needs. Responding to earthquake on this scale is thus easier than the two previous ones.

In order to determine the priority of the activities performed on each scale of earthquake (structure of activities, Figure 5), AHP technique was utilized. Therefore, several tables were designed for pairwise comparison of these activities on each scale of earthquake. These tables were given to 15 experts and

Table 3. The necessity of activities in a response to an earthquake.

\begin{tabular}{|c|c|c|c|}
\hline Subgroup/activity & $\begin{array}{c}\text { Small } \\
\text { earthquake }\end{array}$ & $\begin{array}{c}\text { Medium } \\
\text { earthquake }\end{array}$ & $\begin{array}{c}\text { Large } \\
\text { earthquake }\end{array}$ \\
\hline Initial setup & + & + & + \\
\hline Initial identification & + & + & + \\
\hline Locating focal points & - & + & + \\
\hline Estimating activities & + & + & + \\
\hline Estimating relief crews and equipment & + & + & + \\
\hline Estimating needs and the number of injuries & + & + & + \\
\hline Estimating deficiencies & - & - & + \\
\hline Planning activities & + & + & + \\
\hline Planning relief crews and equipment & - & + & + \\
\hline Planning logistics of needs and injuries & - & + & + \\
\hline Planning response continuity & + & + & + \\
\hline Executing activities & + & + & + \\
\hline Dispatching relief crews and equipment & + & + & + \\
\hline Organizing local relief crews & - & + & + \\
\hline Extricating corpses and wounded people & + & + & + \\
\hline Providing and dispatching needs & + & + & + \\
\hline Transporting wounded people & + & + & + \\
\hline Temporary relocating affected people & + & + & + \\
\hline Supporting and surveillance activities & + & + & + \\
\hline Coordinating to collect public assistance & - & - & + \\
\hline Replacing surplus commodities & - & - & + \\
\hline Analyzing behaviors and evaluating efficiency & + & + & + \\
\hline
\end{tabular}

+ : required; -: is not required. 


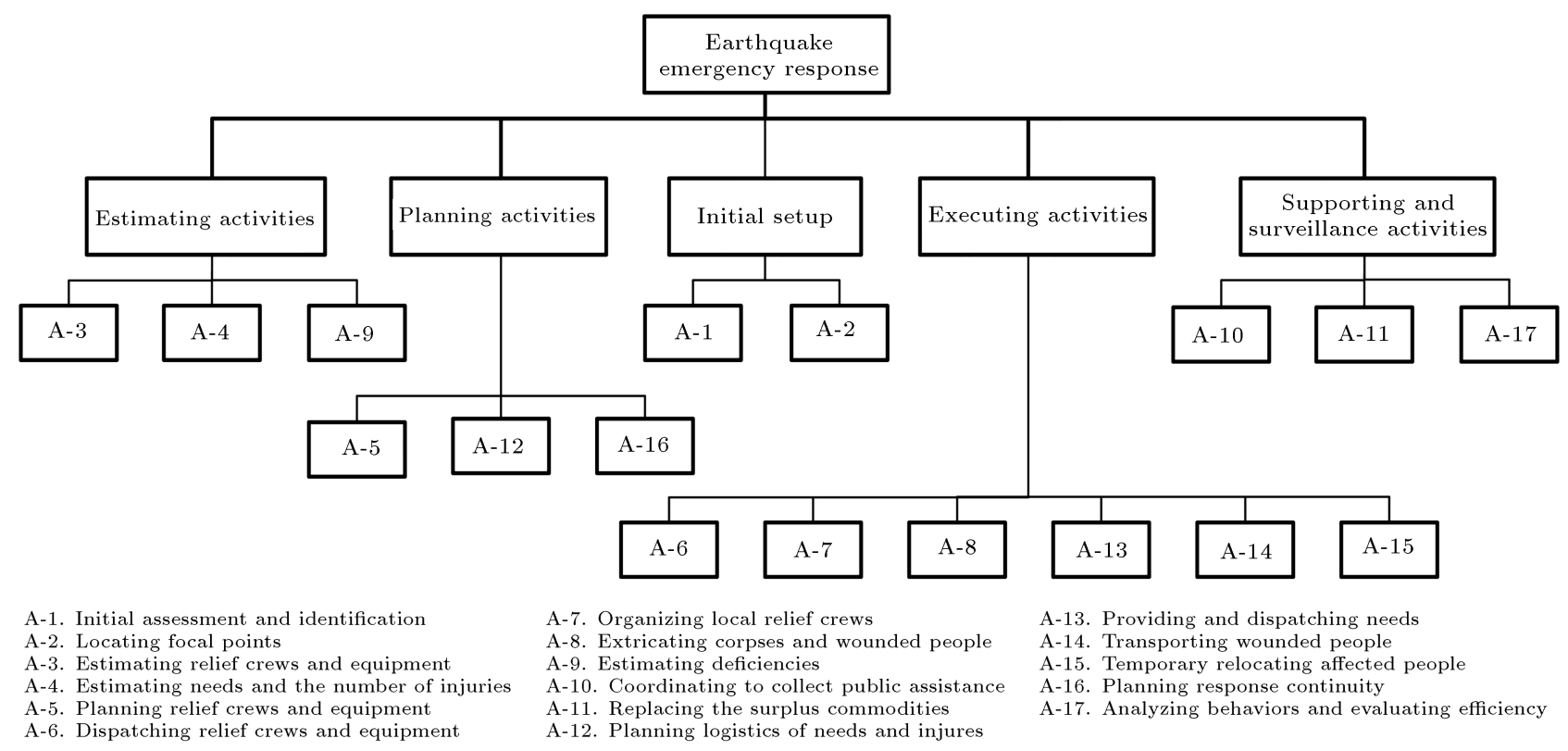

Figure 5. Structure of activities in an earthquake emergency response.

disaster managers in Iran. Afterwards, these pairwise comparisons were analyzed, and any inconsistencies were calculated.

As the data collected from three experts were inconsistent, their opinions were removed. Finally, the opinions of twelve experts were analyzed, and the activities' priority was determined on each scale of earthquake by AHP technique (Table 4).

As expected, the two activities with the highest priority in all earthquake categories are extricating corpses and wounded people (A-8) and transporting wounded people (A-14). Since these activities directly handle human life, any fault in these activities could thus result in loss of life. Moreover, these activities have identical ranks in all responses. However, the priority of the other activities differs in response to various earthquakes. For instance, estimating relief crews and equipment (A-3) and dispatching relief crews and equipment (A-6) have the third and fourth priorities in response to a large or medium earthquake, respectively. However, their priorities are exchanged in a response to a small earthquake. This exchange is expected because a large or a medium earthquake usually imposes large damages. In this case, an exact and precise estimation is important for a proper response. In a small earthquake, however, damages and losses are less than those incurred in a large or a medium earthquake. In this case, estimating relief crews and equipment (A-3) is not vital, and PEC could determine the required crews and equipment based on their experiences. Similar differences are also recognizable in other activities' priorities. Finally, it should be noted that these weights and priorities are calculated by the data collected from twelve disaster managers and experts in Iran. They could be changed or modified in other places considering their specific circumstances.

\section{Conclusion and future research}

The application of an appropriate framework to respond to an earthquake, particularly a large one, can significantly reduce the fatalities and casualties. It also helps responders to manage their resources purposefully and improve the performance of their initial activities. Moreover, if the response plan is comprehensive and integrated, it enables the responder to arrange the organizations involved in the response and decrease the response redundancies and inequalities. In order to achieve this framework for Iran, this paper focused on response activities that should be performed by Planning and Emergency Center (PEC) and proposed an integrated framework (entitled EERF) to improve earthquake emergency response. By designing this framework based on a defined methodology, it was compared to previous research and reports to ensure the lack of conflict between this framework and activities addressed in previous research and reports. Afterward, expert judgments and Analytical Hierarchy Process (AHP) technique were used to measure the priority and importance of each activity in an earthquake emergency response. EERF framework not only helps the PEC to integrate the organizations and individuals involved in an earthquake response, but also assists them to determine the obligations and authorities of organizations involved in response and evaluate them based on their surrendered obligations and authorities. Moreover, using EERF leads to documenting the 
Table 4. Weight and priority of activities in response to an earthquake.

\begin{tabular}{|c|c|c|c|c|c|c|}
\hline \multirow{2}{*}{ Subgroup/activity } & \multicolumn{2}{|c|}{ Small earthquake } & \multicolumn{2}{|c|}{ Medium earthquake } & \multicolumn{2}{|c|}{ Large earthquake } \\
\hline & Weight & Rank & Weight & Rank & Weight & Rank \\
\hline Initial activities & 0.017 & & 0.042 & & 0.029 & \\
\hline Initial identification & 0.017 & 10 & 0.033 & 10 & 0.019 & 12 \\
\hline Locating focal points & - & - & 0.009 & 13 & 0.010 & 15 \\
\hline Estimating activities & 0.143 & & 0.213 & & 0.230 & \\
\hline Estimating relief crews and equipment & 0.095 & 4 & 0.160 & 3 & 0.149 & 3 \\
\hline Estimating needs and the number of injuries & 0.048 & 9 & 0.053 & 8 & 0.066 & 6 \\
\hline Estimating deficiencies & - & - & - & - & 0.015 & 13 \\
\hline Planning activities & 0.051 & & 0.092 & & 0.099 & \\
\hline Planning relief crews and equipment & - & - & 0.030 & 11 & 0.030 & 9 \\
\hline Planning logistics of needs and injuries & - & - & 0.054 & 7 & 0.063 & 7 \\
\hline Planning response continuity & 0.051 & 8 & 0.008 & 14 & 0.006 & 16 \\
\hline Executing activities & 0.697 & & 0.613 & & 0.599 & \\
\hline Dispatching relief crews and equipment & 0.080 & 6 & 0.123 & 4 & 0.118 & 4 \\
\hline Organizing local relief crews & - & - & 0.019 & 12 & 0.028 & 10 \\
\hline Extricating corpses and wounded people & 0.212 & 1 & 0.163 & 1 & 0.161 & 1 \\
\hline Providing and dispatching needs & 0.154 & 3 & 0.089 & 5 & 0.083 & 5 \\
\hline Transporting wounded people & 0.196 & 2 & 0.161 & 2 & 0.156 & 2 \\
\hline Temporary relocating affected people & 0.055 & 7 & 0.058 & 6 & 0.053 & 8 \\
\hline Supporting and surveillance activities & 0.092 & & 0.04 & & 0.043 & \\
\hline Coordinating to collect public assistance & - & - & - & - & 0.012 & 14 \\
\hline Replacing surplus commodities & - & - & - & - & 0.027 & 11 \\
\hline Analyzing behaviors and evaluating efficiency & 0.092 & 5 & 0.040 & 9 & 0.004 & 17 \\
\hline
\end{tabular}

experiences and knowledge obtained in a response to improve the next earthquake response.

Although this framework was proposed for responding to an earthquake in Iran, other Middle East countries with a similar structure, including Pakistan and Iraq, can use it. In order to achieve a comprehensive framework, other researchers are encouraged to improve EERF and provide the best practice for earthquake response. In addition, due to the impact of estimation techniques on quality of earthquake emergency response, designing a mechanism to predict the relief crews and equipment required in response, injured persons, and survivors' needs is recommended for future research. Finally, as indicated above, time is a critical factor in response. Thus, the responder must know the necessary time for an activity of EERF on various scales of earthquake. Therefore, another suggestion for future research is determining rational duration times for EERF activities on various scales of earthquake.

\section{Acknowledgements}

The authors would like to thank Iranian Red Crescent, and National Disaster Management Organization of Iran for their guidance, inspiration, and constructive feedback during this study.

\section{References}

1. Akkihal, A. "Inventory pre-positioning for humanitarian operations", Thesis for Degree of Master of Engineering in Logistics, Massachusetts Institute of Technology (2006).

2. Eshghi, K. and Larson, R.C. "Disaster: lessons from the past 105 years", Disaster Prevention and Management, 17(1), pp. 62-82 (2008).

3. Tzeng, G., Cheng, H., and Huang, T.D. "Multiobjective optimal planning for designing relief delivery systems", Transportation Research Part E: Logistics and Transportation Review, 43, pp. 673-686 (2007). 
4. Ahmadi, M.H. and Sadeghi, N. "Mental health preparedness for natural disasters in Iran", Natural Hazards, 44, pp. 243-252 (2008).

5. Lixin, Y., Lingling, G., Dong, Z., Junxue, Z., and Zhanwu, G. "An analysis on disasters management system in China", Natural Hazards, 60, pp. 295-309 (2012).

6. King, D. "Organizations in disaster", Natural Hazards, 40, pp. 657-665 (2007).

7. Nateghi-A., F. "Existing and proposed earthquake disaster management organization for Iran", Disaster Prevention and Management, 9(3), pp. 200-204 (2000).

8. Tseng, C.P. and Chen, C.W. "Natural disaster management mechanisms for probabilistic earthquake loss", Natural Hazards, 60, pp. 1055-1063 (2012).

9. Prater, C. and Wu, J.Y. "The politics of emergency response and recovery: preliminary observations on Taiwan's 921 earthquake", The Australian Journal of Emergency Management, 17(3), pp. 48-59 (2002).

10. Loosemore, M. and Hughes, W.P. "Confronting social defense mechanisms: avoiding disorganization during crises", Journal of Contingencies and Crisis Management, 9(2), pp. 73-87 (2001).

11. Palmer, M. "Doing it by the book: a paradox in disaster management", The Australian Journal of Emergency Management, 16(3), pp. 40-44 (2001).

12. Carr, J. and Jensen, J. "Explaining the pre-disaster integration of Community Emergency Response Teams (CERTs)", Natural Hazards, 77, pp. 1551-1571 (2015).

13. Veysmoradi, D., Vahdani, B., Farhadi Sartangi, M., and Mousavi, S., "Multi-objective open locationrouting model for relief distribution networks with split delivery and multi-mode transportation under uncertainty", Scientia Iranica, 25(6), pp. 3635-3653 (2017). DOI: $10.24200 /$ sci.2017.4572

14. Alem, D., Clark, A., and Moreno, A. "Stochastic network models for logistics planning in disaster relief", European Journal of Operational Research, 255(1), pp. 187-206 (2016).

15. Tofighi, S., Torabi, S.A., and Mansouri, S.A. "Humanitarian logistics network design under mixed uncertainty", European Journal of Operational Research, 250(1), pp. 239-250 (2016).

16. Özdamar, L. and Ertem, A.M. "Models, solutions and enabling technologies in humanitarian logistics", European Journal of Operational Research, 244(1), pp. 55-65 (2015).

17. D'Uffizi, A., Simonetti, M., Stecca, G., and Confessore, G. "A simulation study of logistics for disaster relief operations", Procedia CIRP, 33, pp. 157-162 (2015).

18. Najafi, M., Eshghi, K., and Leeuw de, S. "A dynamic dispatching and routing model to plan/re-plan logistics activities in response to an earthquake", OR Spectrum, 36, pp. 323-356 (2014).

19. Wisetjindawat, W., Ito, H., Fujita, M., and Eizo, H. "Planning disaster relief operations", Procedia - Social and Behavioral Sciences, 125, pp. 412-421 (2014).

20. Najafi, M., Eshghi, K., and Dullaert, W. "A multiobjective robust optimization model for logistics planning in the earthquake response phase", Transportation Research Part E: Logistics and Transportation Review, 49(1), pp. 217-249 (2013).

21. Bozorgi-Amiri, A., Jabalameli, M.S., and Mirzapour Al-e-Hashem S.M.J. "A multi-objective robust stochastic programming model for disaster relief logistics under uncertainty", OR Spectrum, 35, pp. 905-933 (2013).

22. Zhang, J.H., Li, J., and Liu, Z.P. "Multiple-resource and multiple-depot emergency response problem considering secondary disasters", Expert Systems with Applications, 39(12), pp. 11066-11071 (2012).

23. Wohlgemuth, S., Oloruntoba, R., and Clausen, U. "Dynamic vehicle routing with anticipation in disaster relief", Socio-Economic Planning Sciences, 46(4), pp. 261-271 (2012).

24. Rottkemper, B., Fischer, K., and Blecken, A. "A transshipment model for distribution and inventory relocation under uncertainty in humanitarian operations", Socio-Economic Planning Sciences, 46(1), pp. 98-109 (2012).

25. Tricoire, F., Graf, A., and Gutjahr, W.J. "The biobjective stochastic covering tour problem", Computers and Operations Research, 39(7), pp. 1582-1592 (2012).

26. Hamedi, M., Haghani, A., and Yang, S. "Reliable transportation of humanitarian supplies in disaster response: model and heuristic", Procedia-Social and Behavioral Sciences, 54, pp. 1205-1219 (2012).

27. Jotshi, A., Gong, Q., and Batta, R. "Dispatching and routing of emergency vehicles in disaster mitigation using data fusion", Socio-Economic Planning Sciences, 43, pp. 1-24 (2009).

28. Stepanov, A. and Smith, J.M. "Multi-objective evacuation routing in transportation networks", European Journal of Operational Research, 198, pp. 435-446 (2009).

29. Sheu, J. "An emergency logistics distribution approach for quick response to urgent relief demand in disasters", Transportation Research Part E: Logistics and Transportation Review, 43, pp. 687-709 (2007).

30. Chang, M., Tseng, Y., and Chen, J. "A scenario planning approach for the flood emergency logistics preparation problem under uncertainty", Transporta- 
tion Research Part E: Logistics and Transportation Review, 43, pp. 737-754 (2007).

31. Yi, W. and Ozdamar, L. "A dynamic logistics coordination model for evacuation and support in disaster response activities", European Journal of Operational Research, 179(3), pp. 1177-1193 (2006).

32. Barbarosoglu, G. and Arda, Y. "A two-stage stochastic programming framework for transportation planning in disaster response", Journal of Operational Research Society, 55, pp. 43-53 (2004).

33. Ozdamar, L., Ekinci, E., and Kucukyazici, B. "Emergency logistics planning in natural disasters", Annals of Operations Research, 129, pp. 217-245 (2004).

34. Barbarosoglu, G., Ozdamar, L., and Cevik, A. "An interactive approach for hierarchical analysis of helicopter logistics in disaster relief operations", European Journal of Operation Research, 140, pp. 118-133 (2002).

35. Oh, S. and Haghani, A. "Formulation and solution of a multi-commodity, multi-modal network flow model for disaster relief operations", Transportation Research Part A: Policy and Practice, 30, pp. 231-250 (1996).

36. Oh, S. and Haghani, A. "Testing and evaluation of a multi-commodity multi-modal network flow model for disaster relief management", Journal of Advanced Transportation, 31, pp. 249-282 (1997).

37. Najafi, M., Zanjirani, F.R., Brito, M.P.D., and Dullaert, W. "Location and distribution management of relief centers: A genetic algorithm approach", International Journal of Information Technology \& Decision Making, 14(4), pp. 769-803 (2015).

38. Kurita, T., Nakamura, A., and Kodama, M. "Tsunami public awareness and the disaster management system of Sri Lanka", Disaster Prevention and Management, 15(1), pp. 92-110 (2006).

39. Helbing, D. and Kuhnert, C. "Assessing interaction networks with applications to catastrophe dynamics and disaster management", Physica A, 328, pp. 584606 (2003).

40. Sotoudeh-Anvari, A., Sadjadi, S., Hadji Molana, S., and Sadi-Nezhad, S. "A stochastic multi-objective model based on the classical optimal search model for searching for the people who are lost in response stage of earthquake", Scientia Iranica, 26(3), pp. 1842-1864 (2019). DOI: $10.24200 /$ sci.2018.20226

41. Ma, X., Song, Y., and Huang, J. "Min-max robust optimization for the wounded transfer problem in largescale emergencies", Control and Design Conference, China (2010).

42. Yi, W. and Kumar, A. "Ant colony optimization for disaster relief operations", Transportation Research Part E: Logistics and Transportation Review, 43, pp. 660-672 (2007).
43. Chen, R., Sharman, R., RaghavRao, H., and Upadhyaya, S.J. "Coordination in emergency response management", Commun, ACM 51, 5, pp. 66-73 (2008).

44. Tang, P. and Shen, G.Q. "Decision-making model to generate novel emergency response plans for improving coordination during large-scale emergencies", Knowledge-Based Systems, 90, pp. 111-128 (2015).

45. Zhang, Y., Weng, W.G., and Huang, Z.L. "A scenariobased model for earthquake emergency management effectiveness evaluation", Technological Forecasting and Social Change, 128, pp. 197-207 (2018).

46. Ibrion, M., Mokhtari, M., and Nadim, F. "Earthquake disaster risk reduction in Iran: lessons and "lessons learned" from three large earthquake disasters - Tabas 1978, Rudbar 1990, and Bam 2003", International Journal of Disaster Risk Science, 6, pp. 415-427 (2015).

47. National Disaster Management Organization (NDMO) "Introduction to national disaster management organization of Iran", viewed 15 January 2011, available online at: http://www.ndmo.org/ NewsENBody.aspx?id=2

48. International Federation of Red Cross and Red Crescent Societies (IFRC) "Iran: Bam earthquake, final report", available online at: http://www.ifrc.org/cgi/pdf_appeals.pl?03/2503 interimfinal.pdf (2008).

49. Eshghi, S., Zare, M., Nasserasadi, K., Seyed-Razzaghi, M., et al., Reconnaissance Report on 26 December 2003 $B A M$ Earthquake, International Institute of Earthquake Engineering and Seismology, Iran (2004) (In Persian).

50. Berberian, M. "the 2003 Bam urban earthquake: a predictable seismotectonic pattern along the western margin of the rigid lut block, southeast Iran", Earthquake Spectra, 21(S1), pp. S35-S99 (2005).

51. Keeney, G.B. "Disaster preparedness: What do we do now?", Journal of Midwifery \& Women's Health, 4, pp. $2-6$ (2004).

52. Nappi, M.M.L. and Souza, J.C. "Disaster management: hierarchical structuring criteria for selection and location of temporary shelters", Natural Hazards, 75, pp. 2421-2436 (2015).

53. Fiedrich, F., Gehbauer, F., and Rickers, U. "Optimized resource allocation for emergency response after earthquake disasters", Safety Science, 35, pp. 41-57 (2000).

54. Malteser International, "Haiti earthquake relief activity reports No. 1-No. 6", Available online at: http://maltarelief.org/Media/EmergencyReliefReports. $\operatorname{aspx}(2010)$.

55. Wood, H.O. and Neumann, F. "Modified Mercalli intensity scale of 1931", Bulletin of the Seismological Society of America, 21(4), pp. 277-283 (1931). 
Table A.1. Activities of response.

\begin{tabular}{|c|c|c|c|c|c|}
\hline \multirow[b]{2}{*}{ Activity } & \multirow{2}{*}{$\begin{array}{c}\text { Do you agree } \\
\text { with the } \\
\text { current category? }\end{array}$} & \multirow{2}{*}{$\begin{array}{l}\text { Proposed } \\
\text { category }\end{array}$} & \multicolumn{3}{|c|}{ Is this activity required in } \\
\hline & & & $\begin{array}{l}\text { Large } \\
\text { EQ. }\end{array}$ & $\begin{array}{l}\text { Medium } \\
\text { EQ. }\end{array}$ & $\begin{array}{c}\text { Small } \\
\text { EQ. }\end{array}$ \\
\hline \multicolumn{6}{|c|}{ Initial setup } \\
\hline Initial identification & Yes $\square$ No $\square$ & & Yes $\square$ No $\square$ & Yes $\square$ No $\square$ & Yes $\square$ No $\square$ \\
\hline \multicolumn{6}{|c|}{ Estimating activities } \\
\hline Estimating relief crews and equipment & Yes $\square$ No $\square$ & & Yes $\square$ No $\square$ & Yes $\square$ No $\square$ & Yes $\square$ No $\square$ \\
\hline Estimating needs and the number of injuries & Yes $\square$ No $\square$ & & Yes $\square$ No $\square$ & Yes $\square$ No $\square$ & Yes $\square$ No $\square$ \\
\hline Estimating deficiencies & Yes $\square$ No $\square$ & & Yes $\square$ No $\square$ & Yes $\square$ No $\square$ & Yes $\square$ No $\square$ \\
\hline \multicolumn{6}{|c|}{ Planning activities } \\
\hline Planning relief crews and equipment & Yes $\square$ No $\square$ & & Yes $\square$ No $\square$ & Yes $\square$ No $\square$ & Yes $\square$ No $\square$ \\
\hline Planning logistics of needs and injuries & Yes $\square$ No $\square$ & & Yes $\square$ No $\square$ & Yes $\square$ No $\square$ & Yes $\square$ No $\square$ \\
\hline Planning response continuity & Yes $\square$ No $\square$ & & Yes $\square$ No $\square$ & Yes $\square$ No $\square$ & Yes $\square$ No $\square$ \\
\hline \multicolumn{6}{|c|}{ Executing activities } \\
\hline Dispatching relief crews and equipment & Yes $\square$ No $\square$ & & Yes $\square$ No $\square$ & Yes $\square$ No $\square$ & Yes $\square$ No $\square$ \\
\hline Organizing local relief crews & Yes $\square$ No $\square$ & & Yes $\square$ No $\square$ & Yes $\square$ No $\square$ & Yes $\square$ No $\square$ \\
\hline Extricating corpses and wounded people & Yes $\square$ No $\square$ & & Yes $\square$ No $\square$ & Yes $\square$ No $\square$ & Yes $\square$ No $\square$ \\
\hline Providing and dispatching needs & Yes $\square$ No $\square$ & & Yes $\square$ No $\square$ & Yes $\square$ No $\square$ & Yes $\square$ No $\square$ \\
\hline Transporting wounded people & Yes $\square$ No $\square$ & & Yes $\square$ No $\square$ & Yes $\square$ No $\square$ & Yes $\square$ No $\square$ \\
\hline Temporary relocating affected people & Yes $\square$ No $\square$ & & Yes $\square$ No $\square$ & Yes $\square$ No $\square$ & Yes $\square$ No $\square$ \\
\hline \multicolumn{6}{|c|}{$\begin{array}{c}\text { Supporting and surveillance } \\
\text { activities }\end{array}$} \\
\hline Coordinating to collect public assistance & Yes $\square$ No $\square$ & & Yes $\square$ No $\square$ & Yes $\square$ No $\square$ & Yes $\square$ No $\square$ \\
\hline Analyzing behaviors and evaluating efficiency & Yes $\square$ No $\square$ & & Yes $\square$ No $\square$ & Yes $\square$ No $\square$ & Yes $\square$ No $\square$ \\
\hline \multicolumn{6}{|c|}{ Do you have any suggestion for new activity? } \\
\hline \multirow{4}{*}{ New Activity } & \multirow{4}{*}{$\begin{array}{c}\text { Purpose } \\
\text { of activity? }\end{array}$} & & \multicolumn{3}{|c|}{ Is this activity required in } \\
\hline & & & $\begin{array}{l}\text { Large } \\
\text { EQ. }\end{array}$ & $\begin{array}{l}\text { Medium } \\
\text { EQ. }\end{array}$ & $\begin{array}{c}\text { Small } \\
\text { EQ. }\end{array}$ \\
\hline & & & Yes $\square$ No $\square$ & Yes $\square$ No $\square$ & Yes $\square$ No $\square$ \\
\hline & & & Yes $\square$ No $\square$ & Yes $\square$ No $\square$ & Yes $\square$ No $\square$ \\
\hline
\end{tabular}

\section{Appendix}

The questionnaire utilized to determine the necessity of activities on various scales of earthquake is shown in Table A.1.

\section{Biographies}

Mehdi Najafi is an Assistant Professor of Industrial Engineering Department at Sharif University of Technology, Tehran, Iran. He received his $\mathrm{PhD}$ in the field of Operations Research from Sharif University of Technology in 2012. His research interest is application of operations research to problems related to disaster and healthcare operations management.

Sassan Eshghi is an Associate Professor at Interna- tional Institute of Earthquake Engineering and Seismology, Tehran, Iran. He received his $\mathrm{PhD}$ in the field of Civil Engineering from University of Bristol in 1998. His fields of interest include seismic design of special structures, strengthening of existing structures for seismic resistance, seismic design of reinforced concrete structure, and lifeline earthquake engineering.

Kourosh Eshghi is a Professor of Industrial Engineering Department at Sharif University of Technology, Tehran, Iran. He received his $\mathrm{PhD}$ in the field of Operations Research from University of Toronto in 1997. He has been the Head of IE Department for 7 years. His fields of interest include graph theory, integer programming, and combinatorial optimization problems. He is the author of 6 books and over 80 international journal papers. 